\title{
Effect of sterilization treatment on polyphenol content, antioxidant activity and stability of free and encapsulated herb (Terminalia arjuna) added milk drink
}

\author{
Pravin Digambar Sawale, Girdhari Ramdas Patil, Shaik Abdul Hussain, Ashish Kumar Singh and Ram Ran Bijoy Singh
}

Received: 17 October 2018 / Accepted: 26 December 2018 / Published online: 18 April 2019

(C) Indian Dairy Association (India) 2019

\begin{abstract}
In the current investigation, effect of heat treatment $\left(121^{\circ} \mathrm{C} / 15 \mathrm{~min}\right)$ on stability, polyphenols content and antioxidant activity of milk drinks added with alcoholic extract Terminalia arjuna were determined. Four different vanilla chocolate flavoured milk drink samples viz. supplemented with free (Drink 1) and encapsulated (Drink 2) form of T. arjuna and their respective controls (Control $1 \&$ Control 2) devoid of herbal extract were prepared. The sterilization treatment reduced the antioxidant activity and phenolic content of drink 1, while reverse trend was noticed for drink 2 . Heat coagulation time, measure of stability of milk drinks, revealed that addition of $T$. arjuna extract led to a decrease in $\mathrm{pH}$ (Drink $1-\mathrm{pH} 6.67$ to 6.65 and Drink $2-\mathrm{pH} 6.67$ to 6.66) of milk drinks thus led to destabilization of casein micelles as evidenced from the appearance of flakes in heat stability tubes. Control samples showed type A kind of HCT-pH profile, while Drink 1 and Drink 2 showed type B kind of HCT-pH profile. The study indicated that encapsulation is effective in preserving the bioactivity of T. arjuna extract during heat treatment.
\end{abstract}

Keywords: Antioxidant activity, Encapsulation, Polyphenols, Stability, Terminalia arjuna

\footnotetext{
Pravin Digambar Sawale $(\bowtie)$

Dairy Technology,

College of Dairy Technology, Warud (Pusad)-445204, MAFSU, Nagpur

E-mail: pravins92@gmail.com; Phone : +91-8469367101
}

Girdhari Ramdas Patil, Shaik Abdul Hussain, Ashish Kumar Singh and Ram Ran Bijoy Singh

Dairy Technology Division, ICAR-National Dairy Research Institute, Karnal-132 001, Haryan, India

\section{Introduction}

Terminalia arjuna (TA) is an important medicinal plant that has been used in Ayurvedic and Indian traditional medicine since ages. TA is chemically rich with its varied content of active compounds such as phytosterols, saponins, flavonoids (arjunone, arjunolone, luteolin), gallic acid, tannin and many other useful polyphenols (Miller, 1998). TA plant has been used as an antioxidant, antithrombotic, hypolipidemic, immunomodulatory, liver tonic, diuretic, hypocholesterolemic, anti-carcinogenic and anti-inflammatory agent (Lampronti et al., 2008). Due to their potent health benefits, herbal extracts are currently being extensively explored for use in functional foods development (Hussain et al., 2017). However, TA extracts possess an unpleasant flavour, bitter taste and abnormal red colour which may hamper its supplementation in food products. Ayurveda also considered milk as the most effective carrier for delivering bioactive herbal ingredients (Sawale, et al., 2013 \& 2015a). Milkbased beverages are proving to be ideal vehicles for newly discovered bioactive food ingredients (Sharma, 2005; Sawale et al., 2015b). Addition of herbal extracts to milk and subsequent processing treatments may pose a definite challenge during new product development as there are possibilities for varying degree of interactions among the major and minor biomolecules of milk and bioactive compounds in herbs. Such interactions could have beneficial effects but at times these interactions may lead to undesirable changes in food matrix.

The development of novel dairy foods requires novel technologies for incorporating health promoting ingredients into food without reducing their bioavailability or functionality. In many cases, microencapsulation/micro emulsion/nanoemulsion can provide the necessary protection for these compounds. Among these, emulsion based delivery systems are getting more attention now a days due to their efficacy for targeted delivery and better absorption in the human gut. They offer significant advantages over the solids matrix materials as they can be used in liquid food systems. However, stability of nanoemulsions in the complex food environment has been a challenging work. Encapsulation technique appears to be an excellent tool for masking flavour, colour and astringency of herbal extracts during their supplementation into food matrices. Matrix materials used 
during encapsulation viz. proteins and polysaccharides provide a solid support to microcapsule which helps in safeguarding the material present in its core. Till now, no reports available on effect of sterilization treatment on stability of both free and encapsulated TA extracts supplemented in milk drinks.

The objective of this research was to assess the effect of sterilization treatment on the stability and bioactivity of milk drinks supplemented with free and encapsulated TA extract.

\section{Materials and methods}

\section{Materials}

TA bark was obtained from the local market. All other reagents used were of analytical grade.

\section{Preparation of TA extract}

TA bark was cleaned, and ground in an electric colloid mill. Coarse powder obtained was soaked in $50 \%$ alcohol for $72 \mathrm{~h}$ at $5{ }^{\circ} \mathrm{C}$ followed by filtration to obtain a reddish brown syrupy mass. The mass thus obtained was dried in a tray drier at $50^{\circ} \mathrm{C}$ to get fine powder. Alcoholic extract of TA bark powder was then stored in amber coloured bottles at $4{ }^{\circ} \mathrm{C}$ until use. Phytochemical analysis of TA ethanolic extract showed that it has total phenolics $19.49 \%$, tannins $7.44 \%$ and flavonoids $2.65 \%$.

\section{Preparation of TA extract added microcapsules}

The TA extract added microcapsules were prepared as per the method described by Sawale et al. (2017b). In brief, dispersions of maltodextrin (MD $\left.80 \mathrm{~g} \mathrm{~L}^{-1}\right)$ and Gum arabic $\left(20 \mathrm{~g} \mathrm{~L}^{-1}\right)$ were prepared in distilled water. These dispersions were then combined and homogenously with TA extract (@2\%) followed by homogenization using a high shear mixture at $4000 \mathrm{rpm}$ for $5 \mathrm{~min}$ (IKA-T25, Ultra Turrax, Germany) to form microcapsules. The mix was then dried by tray drying at $50^{\circ} \mathrm{C}$ and microcapsule powder obtained was stored in amber coloured bottles at $5{ }^{\circ} \mathrm{C}$ until further use. The encapsulation efficiency measured as percent polyphenol retained by the encapsulated matrix was observed to be $42 \pm 4.2 \mathrm{~g} / 100 \mathrm{~g}$ (Sawale et al. 2017a).

\section{Selection and optimization of process variables for dairy drink}

Fig. 1 Flow chart for preparation of encapsulated Terminalia arjuna extract added vanilla chocolate dairy drink

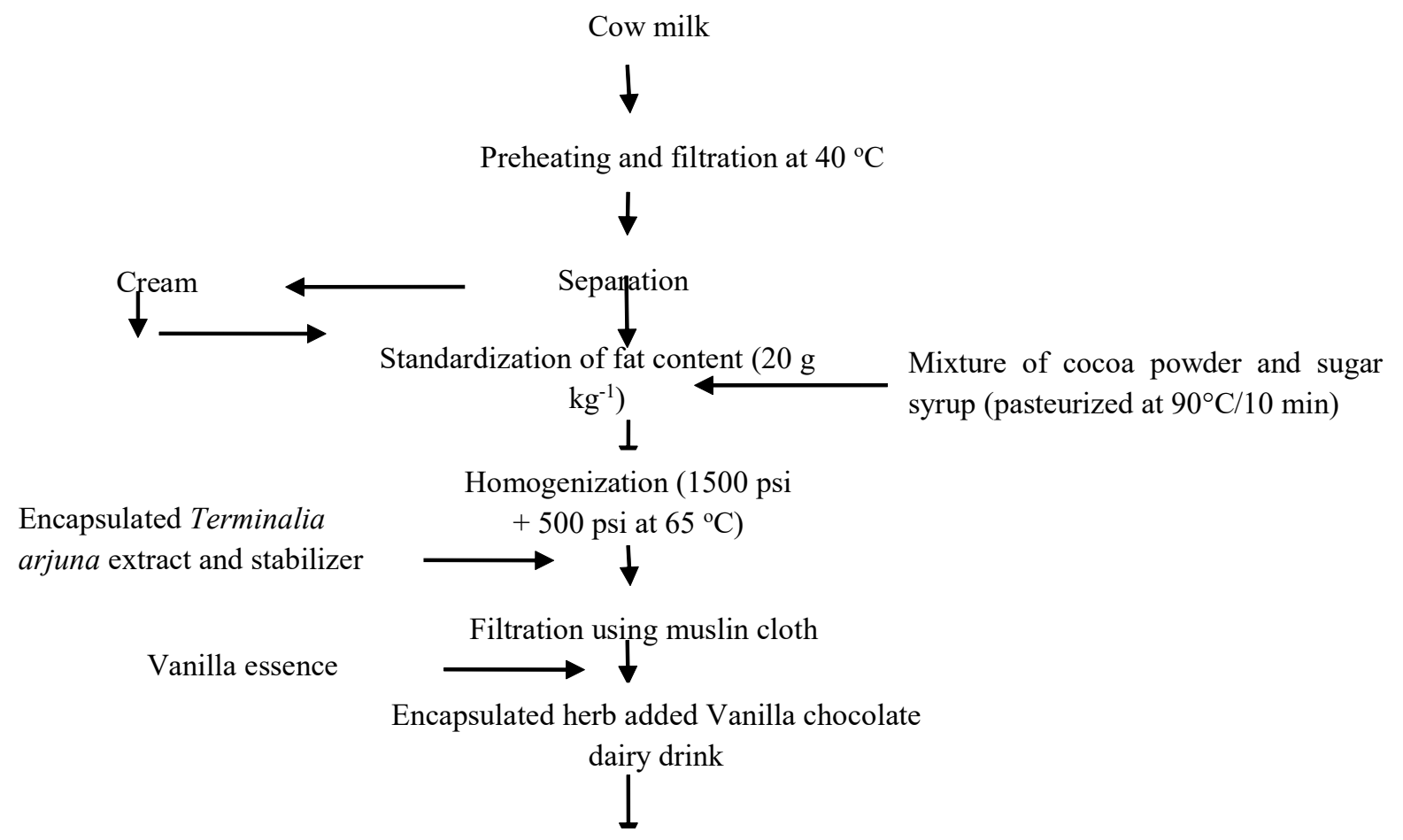

Filling in glass bottles $(200 \mathrm{~mL})$ and capping

Sterilization $\left(121^{\circ} \mathrm{C} / 15 \mathrm{~min}\right)$

Cooling and storage 


\section{preparation}

Encapsulated herb added dairy beverage (drink 2) formulation was optimized with the help of Response Surface Methodology (RSM) using Design Expert 8.0.2 software (Stat Ease Inc., USA). In order to optimize the process for developing dairy drink with enhanced health attributes, the influence of levels of each of the three variables namely encapsulated herb, cocoa powder and sweetener level on physicochemical and sensory properties of drink was investigated. The levels of variables were selected on the basis of sensory evaluation, $\mathrm{pH}$, viscosity, colour and sediment. Twenty experiments were designed according to the response surface methodology using CCRD design of RSM. Further, stabilizer and vanilla were added in final optimized product for further enhancing the acceptability of herbal dairy drink 2 .

\section{Preparation of dairy drinks}

The different samples of dairy drinks i.e. drink 1, drink 2, control 1 and control 2 were prepared as per the procedure given in Figure 1 (Sawale et al. 2017b). For drink 2 and drink 1 preparation encapsulated and free Terminalia arjuna extracts were added to the formulation, respectively. Respective controls of drink 1 and drink 2 i.e. control 1 and control 2 samples were prepared by excluding the herbal extract addition to the drink formulation given in Figure 1. The proximate composition of the different drinks is depicted in Table1. Proximate composition of dairy drinks and their controls is given in Table 2.

\section{Antioxidant activity and polyphenol content of dairy drinks}

\section{DPPH radical scavenging activity}

Antioxidant capacity of dairy drinks was analyzed based on DPPH (2, 2 diphenyl-1-picryl hydrazyl) radical scavenging as per the method given by Williams et al. (1995). $100 \mathrm{iL}$ of appropriate dilution of sample, $(1: 10) /$ trolox solution was mixed with $4.0 \mathrm{~mL}$ of freshly prepared DPPH working solution in $10 \mathrm{~mL}$ test tube; the contents were vortexes and incubated in dark for $30 \mathrm{~min}$ at $37^{\circ} \mathrm{C}$ after covering the test tube with aluminium foil. The absorbance of the solution was measured at $515 \mathrm{~nm}$ against methanol using SPECORD-200 double beam spectrophotometer (Analytical Zena Germany). For blank determination 100 iL methanol was taken instead of sample and absorbance was measured immediately against methanol.

\section{Antioxidant capacity using ABTS method}

The free radical scavenging activity of dairy drinks was determined by ABTS (2, 2-Azinobis (3-ethylbenzo-thiazoline) -6sulfonic acid) method as explained by Re et al. (1999). Three mL of ABTS wor0king solution made with PBS ( $\mathrm{pH} 7.4)$ was added to cuvette ( $3 \mathrm{~mL}$ capacity) and absorbance adjusted to $0.7 \pm 0.02$ against the buffer. $4 \mu \mathrm{L} / \mathrm{mL}$ of sample was added to ABTS working solution as well as in the blank. The contents were mixed for 5 seconds and change in absorbance at $734 \mathrm{~nm}$ was recorded over 10 min using SPECORD-200 double beam spectrophotometer (Analytical Zena, Germany).

\section{Total phenolic content}

Total phenolic content of drinks was analyzed by the FolinCiocalteu method illustrated by Kahkonen et al. (1999). 400

Table 1 Formulations of differnt vanilla chocalate dairy drinks

\begin{tabular}{llllc}
\hline Constituent (\%) & Control 1 & Drink 1 & Control 2 & Drink 2 \\
\hline Herb & - & 0.3 & - & 0.3 \\
Cocoa powder & 0.7 & 0.7 & 0.97 & 0.97 \\
Sugar & 6.85 & 6.85 & 7.00 & 7.00 \\
Stabilizer & 0.03 & 0.03 & 0.03 & 0.03 \\
Vanilla essence & 0.05 & 0.05 & 0.05 & 0.05 \\
\hline
\end{tabular}

Data are presented as means \pm SEM ( $n=3)$. D1: Drink added with free herb; C1: Control for D1; D2: Drink added with encapsulated herb; Drink C2: Control for D2

Table 2. Proximate composition of dairy drinks and their control samples

\begin{tabular}{llllc}
\hline Constituent $(\%)$ & Control 1 & Drink1 & Control 2 & Drink2 \\
\hline Fat & $2.10 \pm 0.10^{\mathrm{a}}$ & $2.07 \pm 0.06^{\mathrm{a}}$ & $2.17 \pm 0.17^{\mathrm{a}}$ & $2.03 \pm 0.06^{\mathrm{a}}$ \\
Protein & $3.60 \pm 0.10^{\mathrm{a}}$ & $3.67 \pm 0.15^{\mathrm{a}}$ & $3.63 \pm 0.29^{\mathrm{a}}$ & $3.63 \pm 0.12^{\mathrm{a}}$ \\
Ash & $1.73 \pm 1.37^{\mathrm{a}}$ & $1.78 \pm 1.07^{\mathrm{a}}$ & $1.64 \pm 0.11^{\mathrm{a}}$ & $1.79 \pm 0.10^{\mathrm{a}}$ \\
Total carbohydrates & $10.52 \pm 1.38^{\mathrm{a}}$ & $10.55 \pm 0.63^{\mathrm{a}}$ & $10.76 \pm 0.4^{\mathrm{b}}$ & $13.66 \pm 0.26^{\mathrm{c}}$ \\
Total solids & $17.95 \pm 0.12^{\mathrm{a}}$ & $18.05 \pm 0.66^{\mathrm{a}}$ & $18.21 \pm 0.97^{\mathrm{b}}$ & $21.15 \pm 0.58^{\mathrm{c}}$ \\
\hline
\end{tabular}


$\mu \mathrm{L}$ of appropriately diluted sample/gallic acid standard $(1 \mathrm{mg} / \mathrm{mL}$ in ethanol) was taken in a test tube. To it added $2000 \mu \mathrm{L}$ of diluted Folin-Ciocalteu reagent $(0.2 \mathrm{~N})$ and mixed with vortex mixer. After $3 \mathrm{~min} 1600 \mu \mathrm{L}$ of $\mathrm{Na}_{2} \mathrm{CO}_{3}(7.5 \% \mathrm{w} / \mathrm{v})$ solution was added and incubated under dark at room temperature for $30 \mathrm{~min}$. for blank preparation $400 \mu \mathrm{L}$ of distilled water was taken instead of sample. The absorbance of the samples was measured against blank at $765 \mathrm{~nm}$ using SPECORD-200 double beam spectrophotometer (SPECORD, Analytical Zena, Germany).

\section{Heat stability}

Heat stability of encapsulated and free TA extract added and dairy drinks was determined using heat coagulation time (HCT) vs $\mathrm{pH}$ profile test described by Davies and White (1966).

\section{Statistical analysis}

All the experiments were carried out in triplicate $(n=3)$. All the values were expressed as mean \pm SEM (Standard Error Mean) and significant differences (at $\mathrm{P}<0.05$ ) among groups were determined by one-way analysis of variance (ANOVA) using SYSTAT 6.0.1 software. The means were tested for significance by Post hoc Test (Bonferroni adjustment).

\section{Results and discussion}

\section{Antioxidant activity and polyphenol content of dairy drinks}

The effect of sterilization $\left(121^{\circ} \mathrm{C} / 15 \mathrm{~min}\right)$ treatment on polyphenol content and antioxidant activity is shown in Fig. 2. Sterilization treatment significantly $(\mathrm{p}<0.05)$ affected the polyphenol content and antioxidant activities of both the drinks i.e. drink 1 and drink 2. Control samples i.e. flavoured milk beverages without the addition of herb extracts (free and encapsulated forms) have also been tested for antioxidant activity and polyphenol content along with their herb added counter parts. From Fig. 2, it is evident that addition of herb had significantly $(p<0.05)$ affected the antioxidant activity and polyphenol content of the drinks. Except in case of drink 1 (free herb added beverage), polyphenol content and antioxidant activity (tested by ABTS and DPPH methods) significantly $(\mathrm{p}<0.05)$ increased for the remaining drinks after sterilization treatment. In case of control 1, control 2 and drink 2 , the polyphenol content increased by 8.6 percent, 8.9 percent and 2 percent, respectively after sterilization treatment. While in case of drink 1 , the polyphenol content decreased by 0.3 percent after sterilization treatment.

According to Gad and Salem (2010), addition of green tea and rosemary extract to skim milk significantly increased the antioxidant activity of skim milk. They also reported that the antioxidant activity and phenol content increased after heat treatment of skim milk. The changes in antioxidant activity and phenol content have been ascribed to the alteration in the chemical bonds of polyphenols and milk protein during heat treatment thus leading to complex formation (Hagerman, et al. 1998). In another study, Soong and Barlow (2004) advocated that formation of phenolic compounds during the heat treatment of herbal formulations might be due to the availability of precursors of phenolic molecules or non-enzymatic inter conversion between phenolic molecules that are subjected to the effects of external factors, such as temperature. Chang et al. (2010) also found an increase in phenolic content in the Ginseng Jung Kwa extract after heat treatment $\left(100^{\circ} \mathrm{C} / 3,6,12 \mathrm{hrs}\right)$. This enhancement in phenolic content could be attributed to increase in free and conjugated phenolic acid and maltol content and /or to the release of bound phenolic acid and maltol during heat processing of herbal formulations (Kang, et al. 2007). In contrast to the above results Ross, et al. (2011) found that when grape seed flour was heated to $\mathrm{e} " 180^{\circ} \mathrm{C}$, significant decreases in the total phenolic content and antioxidant activity (measured using FRAP, DPPH, and TEAC) was observed. The results indicated that the thermolabile components present in herbs and their interactions were responsible for the majority of the antioxidant activity.

In the present study, increase in phenolic content of drink 2 could be due to the release of the bound phenolic compounds of Terminalia arjuna extract from encapsulation matrix during sterilization at $121^{\circ} \mathrm{C} / 15 \mathrm{~min}$. However, decrease in phenolic content noticed in case of drink 1 could be attributed to the heat induced degradation/modification of isoflavones occurred due to their direct contact with heat in the absence of protective encapsulation matrix.

\section{Heat stability}

HCT of the drinks 1 and 2 has been evaluated at different $\mathrm{pH}$ values by employing HCT-pH profile test. The results have been depicted in Fig. 3. The addition of alcoholic extract of Herb Terminalia arjuna either encapsulated or free form led to a decrease in $\mathrm{pH}$ (drink 1: $\mathrm{pH} 6.67$ to 6.65 and drink 2: $\mathrm{pH} 6.67$ to 6.66) thus resulted in destabilization of casein micelles as evidenced from the appearance of flakes in heat stability tubes. To obtain HCT-pH profile, $\mathrm{pH}$ of the samples i.e. control and herb added samples was adjusted to $\mathrm{pH}$ from 6.3 to 7.3 using $0.1 \mathrm{~N}$ $\mathrm{NaOH}$ and $0.1 \mathrm{~N} \mathrm{HCl}$. In case of drink 1 and 2 there was decrease in heat stability in the minimum $\mathrm{pH}$ range (6.3 to 6.7) and increase in heat stability in the maximum $\mathrm{pH}$ range (6.7 to 7.3) (Fig. 3). Heat stability of control 1, crink1, control 2 and drink 2 (at $140^{\circ} \mathrm{C}$ ) was $45.67 \mathrm{~min}$., $30.88 \mathrm{~min}$., 55.67 and $49.8 \mathrm{~min}$., respectively at their inherent $\mathrm{pH}$. Control drinks i.e. control 1 and control 2 showed type A kind of profile (maximum and minimum heat stability) while herbal extract supplemented beverages i.e. drink 1 and drink 2 showed type B kind of HCT-pH profile (heat stability increased as a function of $\mathrm{pH}$ ). Control 2 obtained slightly higher heat stability than control 1 at its inherent $\mathrm{pH}$ which could be ascribed to its cocoa powder content. Boomgaard et al. (1987) also reported that cocoa powder slightly increased the heat stability maximum 
Fig. 2 Effect of sterilization treatment on antioxidant activity (ABTS and DPPH) and polyphenol content of different dairy drinks


Data are presented as means $\pm \operatorname{SEM}(n=3)$. Means in each bar with different superscripts $(a, b)$ were significantly different $(\mathrm{P}<0.05)$ from each other. Statistical comparisons were made between samples using ANOVA single factor, TA: Terminalia arjuna, D1: Drink added with free herb, C1: Control 1 for D1, D2: Drink added with encapsulated herb, C2: Control for D2, BS: Before sterilization, AS: After sterilization. 
Fig. 3 HCT-pH profile of dairy drinks

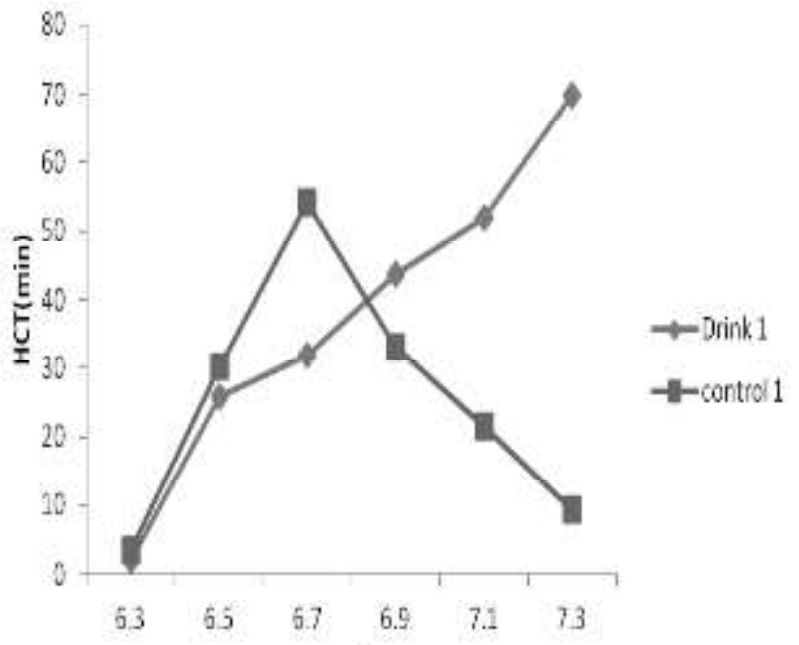

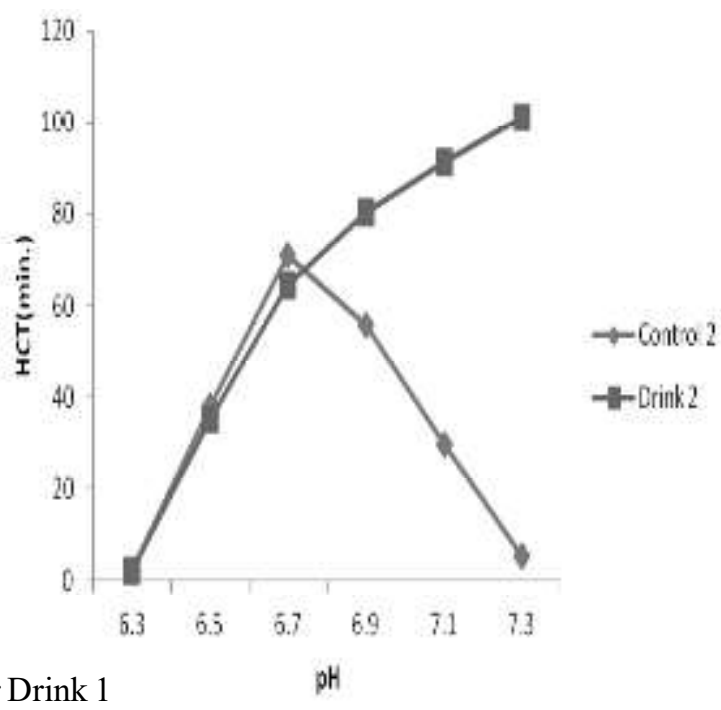

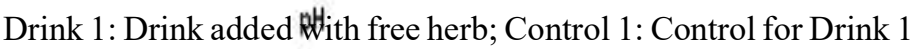

Drink 2: Drink added with encapsulated herb; Control 2: Control for Drink

of chocolate milk but had little effect in the minimum heat stability range.

Results from the present investigation regarding addition of herb on the heat stability of dairy drinks are in accordance with the observations of earlier work of O'Connell et al. (1998) who observed that addition of phenol rich plant extracts i.e. freezedried green tea extract at 0.4 percent $(\mathrm{w} / \mathrm{v})$ and black tea extract at 1.0 percent $(\mathrm{w} / \mathrm{v})$ level increased heat stability of skim milk and converted type A HCT-pH profile to type B HCT-pH by slightly shifting of the HCT-pH profile to more alkaline values at its maximum $\mathrm{pH}$. Interaction of phenolic compounds and thermally generated quinones with nucleophilic amino acids has been implicated in their stabilizing effect of herbal extracts (O'Connell and Fox, 1999). Earlier research related to milk-herb formulations suggested that hydrophobic and hydrogen bonding occurs between polyphenol-protein fractions of herbs and milk components, respectively (Spencer et al., 1988; Haslam and Lilley, 1988). O'Connell et al. (1998) also suggested that the interaction between polyphenols and milk proteins enhance the thermal stability of milk. Chelation of calcium by herbal constituents also appears to be involved in increasing heat stability of milk. The ability of polyphenols to interact covalently with proteins has also been suggested as possible reasons for increased heat stability of milk (Meek and Weiss, 1979).

In the present study, the reason behind the decrease in thermal stability of Drinks 1 and 2 at minimum $\mathrm{pH}(<6.6)$ range could be attributed to change in calcium ions associated with casein micelles and/or interaction between milk proteins and polyphenols present in herb extract. Phytochemicals present in Terminalia arjuna herb extract might have led to shift in the HCT-pH profile to more acidic values in drink 1 and 2 thus causing strong destabilization/dissociation of casein micelle leading to decreased heat stability at lower $\mathrm{pH}$ range. While increase in heat stability at maximum $\mathrm{pH}(>6.6)$ range could be ascribed to association of these phytochemicals to casein micelles thus preventing the micelle aggregation.

\section{Conclusions}

The additions of free and encapsulated Terminalia arjuna into milk beverage at $0.3 \%$ concentration increased the polyphenol content and antioxidant activity while decreased the heat stability of vanilla chocolate dairy drink. The increase in antioxidant activity of drink 2 could be related to release of bound bioactive compounds during heat processing. In case of drink 1 , without encapsulation thermos-labile bioactive components might have been degraded/modified during heat treatment thus led to dissociation of casein micelles. The present study clearly showed that encapsulation matrix had successfully protected herb biomolecules during heat treatment by creating heat stable layer.

\section{Acknowledgements}

First author is highly thankful to Director, NDRI for providing Institutional scholarship and necessary facilities for carrying out this research.

\section{References}

Boomgaard T, Van D, Vliet T, Hooydonk ACM (1987) Physical stability of chocolate milk.Internationa. Journal of Food Science and Technology 22:279-291

Chang, HO, Gyo NK, Sang HL, Jung, SL, Hae DJ ( 2010) Effects of heat processing time on total phenolic content and antioxidant capacity of Ginseng Jung Kwa. Ginseng Research 34(3): 198-204

Davies DT, White JCD (1966) The stability of milk proteins to heat subjective measurement of heat stability of milk. Journal of Dairy Research 33:67-81

Gad AS, Salam MH (2010) The antioxidant properties of skim milk supplemented with rosemary and green tea extracts in response to 
pasteurisation, homogenisation and the addition of salts. International Journal of Dairy Technology 63:1-7

Hagerman, AE, Riedi KM, Jones GA, Sovik KN, Ritchard NT, Hartzfeld PW (1998) High molecular weight plant polyphenolics (tannins) as biological antioxidants. Journal of Agricultural and Food Chemistry 46:1887-1892.

Haslam E, Lilley TH (1988) Natural astringency in foodstuffs: A molecular interpretation. CRC Critical Reviews in Food Science and Nutrition 27: $1-40$

Hussain, SA, Patil GR, Reddi S, Yadav V, Pothuraju R, Singh RRB, Kapila, S (2017) Aloe vera (Aloe barbadensis ) supplemented probiotic lassi prevents Shigella infiltration from epithelial barrier into systemic blood flow in mice model. Microbial Pathogenesis 102:143-147

Kahkonen MP, Hopia AI, Vuorela HJ (1999) Antioxidant activity of plant extracts containing phenolic compounds. Journal of Agricultural and Food Chemistry 47:3954-3962

Kang KS, Yamabe N, Kim HY, Okamoto T, Sei Y, Yokozawa T (2007) Increase in the free radical scavenging activities of American ginseng by heat processing and its safety evaluation. Journal of Ethnopharmacology 113: 225-232

Lampronti MTH, Khan M, Borgatti NB, Gambari R (2008) Inhibitory effects of Bangladeshi medicinal plant extracts on interactions between transcription factors \&target DNA sequences. EvidenceBased Complementary and Alternative Medicine 5(3):303-312

Meek KM, Weiss JB (1979) Differential fixation of poly (L-arginine) and poly(L-lysine) by tannic acid and its application to the fixation of collagen in electron microscopy. Biochimica et Biophysica Acta 587: $112-120$

Miller AL (1998) Botanical influences on cardiovascular disease. Alternative Medicine Review 3(6):422-431

O'Connell, JE, Fox PD, Tan-Kintia R, Fox PF (1998) Effects of tea, coffee and cocoa extracts on the colloidal stability of milk and concentrated milk. International Dairy Journal 8:689-693

O'Connell JE, Fox PF (1999) Effect of extracts of oak (Quercuspetraea) bark, oak leaves, aloe-vera (Curacao aloe), coconut shell and wine on the colloidal stability of milk and concentrated milk. Food Chemistry 66:93-96

Re R, Pellegrini N, Proteggente A, Pannala A, Yang M, Rice-Evans C (1999) Antioxidant activity applying an improved ABTS radical cation decolourization assay. Free Radical Biology and Medicine 26(9/10):1231-1237

Ross CF, Hoye CJ, Fernandez-Plotka VC (2011) Influence of heating on the polyphenolic content and antioxidant activity of grape seed flour. Journal of Food Science 76(6):884-890

Sawale PD, Singh RRB, Arora S (2015a) Stability and quality of Herb (Puerariatuberosa) - milk model. Journal of Food Science and Technology 52(2):1089-1095

Sawale PD, Singh RRB, Kapila S, Arora S, Rastogi S, Rawat AKS (2013) Immunomodulatory and antioxidative potential of herb (Puerariatuberosa) in mice using milk as the carrier. International Journal of Dairy Technology 66 (2):202-206

Sawale, PD, Ramesh P, Shaik HA, Anuj K, Kapila S, Patil GR (2015b) Hypolipidemic and Anti-Oxidative Potential of Encapsulated Herb (Terminalia arjuna) Added Vanilla Chocolate Milk in High Cholesterol Fed Rats. Journal of Science of Food and Agricultural 96(4):13801385. DOI: $10.1002 / j s f a .7234$

Sawale PD, Patil GR, Hussain SA, Singh AK, Singh RRB (2017a) Release Characteristics of Polyphenols from Microencapsulated Terminalia Arjuna Extract: Effects of Simulated Gastric Fluid International Journal of Food Properties 20(12):3170-3178 doi.org/10.1080/ 10942912.2017.1280677

Sawale PD, Patil GR, Hussain SA, Singh AK, Singh RRB (2017b) Effect of incorporation of encapsulated and free herb (Terminalia arjuna) on storage stability of shelf stable chocolate vanilla dairy drinks. Food Bioscience 19:142-148 dx.doi.org/10.1016/j.fbio.2017.07.005

Sharma R (2005) Market trends and opportunities for functional dairy beverages. Australian Journal of Dairy Technology 60(2):196-199

Soong Y, Barlow PJ (2004) Antioxidant activity and phenolic content of selected fruit seeds. Food Chemistry 88:411-417

Spencer CM, Cai Y, Martin R, Gaffney SH, Goulding PN, Magnolato D, Lilley TH, Haslam E (1988) Polyphenol complexation: Some thoughts and observations. Phytochemistry 27:2397-2409

Williams B, Cuvelier M, Berset C (1995) Use of free redical method to evaluate antioxidant activity. LebensmWiss and Technology 28:2530 